\title{
Screening for Prostate Cancer
}

\author{
Otis W. Brawley, $\mathrm{MD}^{1}$, Donna P. Ankerst, $\mathrm{PhD}^{2}$, and lan M. Thompson, $\mathrm{MD}^{3}$
}

\begin{abstract}
In the United States, prostate cancer will affect 1 man in 6 during his lifetime. Since the mid-1980s, screening with the prostate-specific antigen (PSA) blood test has more than doubled the risk of a prostate cancer diagnosis. A decrease in prostate cancer death rates has been observed since that time, but the relative contribution of PSA testing as opposed to other factors, such as improved treatment, has been uncertain. The recent release of 2 large randomized trials suggests that if there is a benefit of screening, it is, at best, small. Methods to assess a man's risk of prostate cancer, including those tools that integrate multiple risk factors, are now available and should be used in risk assessment. Men undergoing screening for prostate cancer may reduce their risk of prostate cancer with finasteride. CA Cancer J Clin 2009;59:000-000. ${ }^{\odot} 2009$ American Cancer Society, Inc.
\end{abstract}

\section{Introduction}

To earn free CME credit or nursing contact hours for successfully completing the online quiz based on this article, go to http://CME.AmCancerSoc.org.

Prostate cancer is the most commonly diagnosed nonskin cancer in American men. It is estimated that 192,280 Americans will be diagnosed with prostate cancer in 2009. More than 27,000 men will die of the disease, making it the second largest cancer killer in men. ${ }^{1}$ Americans have the highest incidence of prostate cancer in the world, partly because the United States is one of the few countries that has widespread prostate cancer screening. To our knowledge, the American male population is the most thoroughly screened population in the world.

\section{A Brief History of Prostate Cancer Screening in the United States}

Prostate cancer has a highly variable natural history, ranging from an indolent and silent entity throughout a man's entire life to one that grows rapidly, metastasizing to lymph nodes and bone, with a median life expectancy of 24 to 36 months after bony metastases are detected..$^{2}$ It is largely asymptomatic until metastases are present.

The medical community has advocated the early detection and treatment of prostate cancer for nearly a century. As early as 1905, the noted urologist Hugh H. Young, MD, concluded that careful digital rectal examination (DRE) could identify prostatic changes that herald the first signs of cancer. ${ }^{3}$ For the next 75 years, this was the only screening test available, but an imperfect one. In a study of 2005 men undergoing regular DRE, we found that greater than two-thirds of those whose disease was detected in this fashion had disease beyond the prostate at the time of diagnosis. ${ }^{4}$

A challenge to the concept of early detection is the range of behaviors of prostate cancers. Since the 1980s, it has been estimated that a man's lifetime risk of death from prostate cancer is approximately $3 \%$ to $4 \% .5,6$

\footnotetext{
${ }^{1}$ Chief Medical Officer, American Cancer Society, Atlanta, GA; ${ }^{2}$ Research Associate Professor, Departments of Urology, Epidemiology, and Biostatistics, The University of Texas Health Science Center at San Antonio, San Antonio, TX; ${ }^{3}$ Professor and Chairman, Department of Urology, The University of Texas Health Science Center at San Antonio, San Antonio, TX.
}

Corresponding author: Ian M. Thompson, MD, Department of Urology, University of Texas Health Science Center at San Antonio, 7703 Floyd Curl Drive, San Antonio, TX 78229; thompsoni@uthscsa.edu

DISCLOSURES: Dr. Thompson serves as a consultant to Veridex. No other conflict of interest relevant to this article was reported.

(c) 2009 American Cancer Society, Inc. doi:10.3322/caac.20026.

Available online at http://cajournal.org and http://cacancerjournal.org 
Conversely, autopsy studies of men who died of noncancer causes have found a high prevalence of prostate cancer. Using varying techniques to assess prostates removed at autopsy, pathologists have reported finding cancer in $3 \%$ to $43 \%$ of men in their 40 s, $14 \%$ to $70 \%$ of men in their 60 s, and $31 \%$ to $83 \%$ of men in their $70 \mathrm{~s} .{ }^{7}$ With a reported median male life expectancy in the United States of 78 years, a crude estimate of a man's lifetime risk of harboring prostate cancer may be between $60 \%$ to $70 \% .{ }^{8}$ Recognizing that only 1 in 30 of these men will die from the disease illustrates the challenge facing us: most prostate cancers will never cause symptoms or death.

In the early 1980s, clinicians reacted with optimism to initial studies using a blood protein, prostate-specific antigen (PSA), as a screening test for this disease because of an increasing death rate and the poor performance of the DRE. 9,10 There were initial concerns regarding its poor specificity in that many men with "high" PSA values underwent biopsy and no cancer was found. Indeed, studies indicated that approximately $25 \%$ of men with a PSA level $>4.0 \mathrm{ng} / \mathrm{mL}$ had cancer. ${ }^{11}$ With the publication of these experiences and the clinical availability of the assays, PSA testing proliferated.

The impact of screening was dramatic, as illustrated in Figure 1. The incidence rate of prostate cancer in the United States spiked initially and then settled into a rate approximately 50\% higher than that preceding screening; the lifetime risk of prostate cancer diagnosis increased from $7.3 \%$ in 1977 to nearly $17 \%$ in $2005.6,12$

Currently, it is estimated that $>55 \%$ of all men age 50 years and older are undergoing a PSA screening

\section{Prostate Cancer 1975-2005}

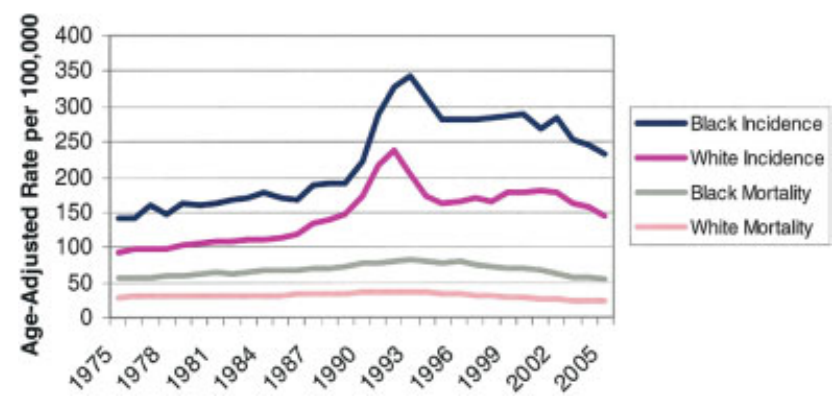

FIGURE 1. US Prostate Cancer Incidence and Mortality Rates by Year From 1975 through 2005. Rates are age-adjusted to the Year 2000 standard. Reprinted with permission from Ries LAG, Melbert D, Krapcho M, et al, eds. SEER Cancer Statistics Review, 1975-2005. Surveillance, Epidemiology, and End Results. Bethesda, Md: National Cancer Institute; 2008.
TABLE 1. US Prostate Cancer Age Distribution, 2001-2005

\begin{tabular}{|l|l|l|}
\hline $\begin{array}{l}\text { AGE, } \\
\text { YEARS }\end{array}$ & $\begin{array}{l}\% \\
\text { DIAGNOSIS }\end{array}$ & $\begin{array}{l}\% \\
\text { DEATH }\end{array}$ \\
\hline $35-44$ & 0.6 & 0.1 \\
\hline $45-54$ & 8.6 & 1.4 \\
\hline $55-64$ & 28 & 6.9 \\
\hline $65-74$ & 36.1 & 20.4 \\
\hline $75-84$ & 22 & 41.5 \\
\hline $85+$ & 4.7 & 29.7 \\
\hline All & 100 & 100 \\
\hline
\end{tabular}

Reprinted with permission from Ries LAG, Melbert D, Krapcho M, et al, eds. SEER Cancer Statistics Review, 1975-2005. Surveillance, Epidemiology, and End Results. Bethesda, Md: National Cancer Institute; 2008.

examination annually and that approximately $75 \%$ have been tested at some point. ${ }^{13,14}$

Prostate cancer is largely a disease of the elderly. Between 2001 and 2005, the median age at diagnosis for white American men was 68 years and the median age at death was 80 years. The median age at diagnosis for black men was 65 years and the median age at death was 77 years. ${ }^{15}$ The age distribution of patients at the time of diagnosis is shown in Table 1 . The number of both black and white men diagnosed before the age of 50 years is small; approximately $2.5 \%$ of white men diagnosed with prostate cancer are aged $<50$ years whereas approximately $5.2 \%$ of black men are aged $<50$ years at the time of diagnosis.

With repeated screening, the majority of prostate cancers detected are clinically localized and, as a result, the number of patients undergoing treatment with radiation and surgery has dramatically increased. ${ }^{16,17}$ Of interest, approximately $90 \%$ of men with localized prostate cancer opt for treatment; $<10 \%$ of men with this disease choose a plan of active surveillance, in which the tumor is carefully monitored and treatment initiated only if evidence of tumor growth is discovered. ${ }^{18}$ There is some evidence that poor and minority patients are less likely to receive aggressive therapy for localized disease. ${ }^{19,20}$ As radiation therapy technology has evolved and with higher volumes of surgical activity, the safety of these treatments has improved since the inception of PSA screening. ${ }^{21}$ Nonetheless, sexual, urinary, and bowel complications do occur with all of these treatments; on occasion, these complications can be severe. ${ }^{22}$ 


\section{What Have Been the Outcomes of This "Experiment" in Screening?}

With an understanding that prostate cancer is virtually ubiquitous in men as they age, it is clear that a goal of "finding more cancers" is not acceptable. Public health principles demand that a minimum of 1 of 3 outcomes must be demonstrated to justify screening. Screening must:

1) Reduce the risk of death from prostate cancer or

2) Reduce the suffering (morbidity) of prostate cancer or

3) Reduce the health care costs when compared with a nonscreening scenario.

Ideally, the first of these outcomes should be achieved. To date, there has been a dramatic increase in the number of cases detected and the number of men treated for prostate cancer. The evidence regarding reductions in death and morbidity is conflicting. In addition to benefits accrued from screening, there must be evidence that any benefits are greater than the known disadvantages, including overdetection, cost, and treatment complications.

Evidence suggesting the effectiveness of screening centers on the clear decrease in mortality rates and the shift toward a lower stage of disease found at diagnosis. Evidence suggesting a lack of effectiveness of screening includes the finding that the mortality reduction occurred so quickly after the introduction of screening and at a time when treatments for even metastatic disease were changing.

Since 1993, there has been a continued decline in the American age-adjusted prostate cancer death rate. The age-adjusted rate per 100,000 population was 39.3 in 1993 and 24.6 in 2005. ${ }^{6}$ Some have suggested that screening, which began in 1989 , is the cause of this decline. Others say that the decline was noted too soon after the initiation of screening and suggest alternative explanations such as the increasing use of hormonal therapies for regional and metastatic disease. Still others suggest the decline in mortality is a cause of death attribution bias. They point to changes in the World Health Organization algorithm for cause of death and an increase in the number of elderly men dying of pneumonia during this same period. ${ }^{23}$ The rise in incidence paralleling the rise in mortality rates and the subsequent drop in incidence with the concurrent decline in mortality also supports the theory that attribution bias may be a factor.

There clearly has been a decrease in the number and rate of prostate cancers staged as metastatic at the time of diagnosis. ${ }^{6}$ This point is tempered by the finding that in some studies of men with localized disease who were treated with radical prostatectomy, as many as $22 \%$ of white men and $33 \%$ of black men developed a PSA recurrence. This suggests that what was believed to be local disease at diagnosis was actually a lower burden of metastatic disease, perhaps a reflection of lead-time bias with screening. ${ }^{24,25}$ Population studies of men treated in the 1990s suggested recurrence rates as high as $35 \% .{ }^{26}$ This is to say that many of those believed to have localized cancer actually had disease extending outside the prostate (either regional or metastatic). One interpretation of these data is that, in the context of intensive PSA screening, prostate cancers with metastases are diagnosed prior to the ability to detect tumor spread. As a result, there may be the appearance of a shift toward a lower stage but ultimately, as metastases become evident, mortality is unaffected.

Results from models and case-control studies have been conflicting in terms of the effectiveness of screening. A simulation model using data from the National Cancer Institute (NCI)'s Surveillance, Epidemiology, and End Results (SEER) registries suggests that screening may account for $45 \%$ to $70 \%$ of the observed decline in mortality. It is not entirely possible to assess the contribution of screening and the contribution of advances in treatment in this model. ${ }^{27}$ Some case-control studies also have suggested that screening does not save lives. One large nested case-control study found no evidence that PSA screening reduces all-cause mortality (odds ratio $[\mathrm{OR}], 1.08 ; 95 \%$ confidence interval [95\% CI], 0.71-1.64). ${ }^{28}$ Two other case-control studies of prostate screening found no statistically significant reduction in prostate-specific mortality (OR, 1.19 [95\% CI, 0.76-1.60] and OR, 0.70 [95\% CI 0.46$1.1]$, respectively). ${ }^{29,30}$ One case-control study found that screening was associated with a decreased risk of metastatic disease at diagnosis. ${ }^{31}$

The decrease in prostate cancer mortality, occurring just 4 to 5 years after screening began, is difficult to attribute to screening when dealing with a disease of such a long natural history and supports alternative explanations for the decline in mortality. During the 
same period as screening proliferated, significant improvements developed in surgery and radiation as well as in the application of hormonal therapies to regional and metastatic disease. One such change was the increased use of gonadotropin-releasing hormone agonists and the use of oral androgen-blocking drugs. ${ }^{32}$ The dramatic increase in the number of localized prostate cancers detected also simply provided physicians with a greater opportunity to hone treatments, increasing their curative nature while focusing as well on reducing toxicities.

Ecologic studies do provide some information with which to put the decline in prostate cancer mortality into perspective. They suggest that screening certainly is not the only cause for the decline in prostate cancer mortality over the past 15 years.

Mass screening was introduced in Tyrol, a state in Austria, in 1993. By 1998, there was a decrease in prostate-specific mortality in Tyrol when compared with the rest of Austria. ${ }^{33}$ It is unclear whether the Tyrol data were affected by differences in the treatment of metastatic disease that may have existed between Tyrol and the rest of Austria.

Age-adjusted prostate cancer mortality rates peaked in 1993 in both the United States and the United Kingdom and began declining at the same rate. Late in the 1990s, the rate of decline became steeper in the United States. Screening is far more common in the United States compared with the United Kingdom. The finding that mortality rates have declined in the United Kingdom, in which screening is not practiced and is actually discouraged, suggests that some, perhaps even most, of the decline in the United States cannot be attributed to screening. ${ }^{34}$

A study of men in the state of Washington compared with men in the state of Connecticut provided some interesting clues regarding the effectiveness of screening. ${ }^{35}$ Medicare beneficiaries in Seattle received far more intensive screening and treatment from 1987 through 1990 compared with their peers in Connecticut. Members of the Seattle cohort were 5.2 times more likely to undergo radical prostatectomy (95\% CI, 3.22-8.42) and 1.24 times more like to be treated with radiation (95\% CI, 0.98-1.58). Men in Seattle were less likely to be treated with hormones (OR, 0.77; 95\% CI, 0.67-0.87). Despite this, the prostate cancer-specific mortality noted over 15 years of follow-up was virtually identical at 1.02 (95\% CI, 0.96-1.09). ${ }^{35}$

\section{The Documented Harms of Screening}

Data clearly indicate that screening leads to the diagnosis of tumors of no clinical significance. Although there are histologic criteria that are used to define "significant" and "insignificant" tumors, the most valid definition of an insignificant tumor is a neoplasm that causes neither symptoms nor death during a patient's lifetime. Overdiagnosis is the detection by screening of disease that would not have become clinically significant. Overdiagnosis significantly affects 5-year survival statistics, making them uninformative in demonstrating progress in cancer control.

A computer modeling study using NCI SEER data estimated that $29 \%$ of cancers detected in whites and $44 \%$ of cancers detected in blacks were overdiagnosed cancers. ${ }^{36} \mathrm{~A}$ similar model using data from the European Randomized Study of Screening for Prostate Cancer (ERSPC) estimated a 50\% overdiagnosis rate. ${ }^{37}$

Patients diagnosed with clinically insignificant tumors are subjected to unnecessary diagnostic tests and unneeded treatment and suffer psychosocial harms. They are also labeled "a cancer patient," which can have negative economic consequences. ${ }^{8,38}$ The lack of data regarding whether screening decreases the risk of death makes quality-of-life issues related to treatment important in the decision-making process regarding whether to be screened.

The mortality rate from radical prostatectomy is reported to be $0.5 \% .{ }^{39}$ The rate approaches $1 \%$ in men aged $>75$ years. ${ }^{40}$ Treatment is also associated with urinary incontinence, sexual dysfunction, and bowel problems. ${ }^{41,42}$ There is evidence that these problems worsen over time. ${ }^{22}$ For radiation therapy and brachytherapy, a wide range of rates of erectile dysfunction (with a median rate between 30\%-50\%), urinary incontinence (ranging from $0 \%$ to $>60 \%$ ), and gastrointestinal toxicity (up to $30 \%$ ) have been reported. ${ }^{43}$

The best way to address the issue of whether prostate cancer screening saves lives is through a well-designed, well-conducted, prospective randomized clinical trial. Two trials, the Prostate, Lung, Colorectal and Ovarian (PLCO) Cancer Screening trial (sample size of 76,693) in the United States and the ERSPC (sample size of 182,160), were initiated 
in the early 1990s and are currently ongoing. Both had interim analyses performed this year.

The American study provided 6 years of annual screening to $>38,000$ men ages 55 to 70 years and observed an equivalent number who were managed according to community standards, ideally with less intensive screening. Because some men who were in the nonscreening group were indeed screened, this is really a comparison of a heavily screened group (85\%) with a less heavily screened group (40\%-50\%). Men in the heavily screened group were diagnosed with $22 \%$ more prostate cancers. After 7 to 10 years of follow-up, no evidence of a mortality benefit for more intensive screening was found (rate ratio, 1.13; 95\% CI, 0.75-1.70). ${ }^{44}$

The European study actually combines 7 studies and totals 182,000 men. Significant variations in screening schedule, age at entry, and other factors are a weakness of this study. Conversely, compared with the US study, the European study had a lower rate of screening in the control group and, as a result, men in the screened arm of the study were diagnosed with $71 \%$ more prostate cancers. The composite European data found a $20 \%$ decrease in prostate cancer mortality associated with screening. This study found that to prevent 1 prostate cancer death, 1,410 men would need to be screened and 48 additional cases of prostate cancer would need to be treated. This finding just barely reaches statistical significance (rate ratio $0.80,95 \% \mathrm{CI}, 0.65-0.98$; adjusted $P=.04.){ }^{45}$

However, a complication exists: could the continued high rate of death from prostate cancer, despite intensive screening, be due to the screening methods and not the "failure" of screening?

As discussed earlier, PSA screening proliferated in the late 1980s after several years of debate as to whether PSA was a good test for detection. Little was known regarding the performance characteristics of the PSA test, such as its rate of detection at varying PSA levels. In addition, the prostate biopsy was still a test in evolution. For example, articles discussing initial PSA screening generally used only 4 randomly placed biopsies of the prostate to determine whether cancer was present. Many cancers were missed when 4 or even 6 biopsies were used. Currently, 10 to 12 biopsy cores are more commonly obtained..$^{9,46}$

Nonetheless, several "rules" for the use of PSA and DRE were developed and persist even today, although we now know that these rules are naïve. The common

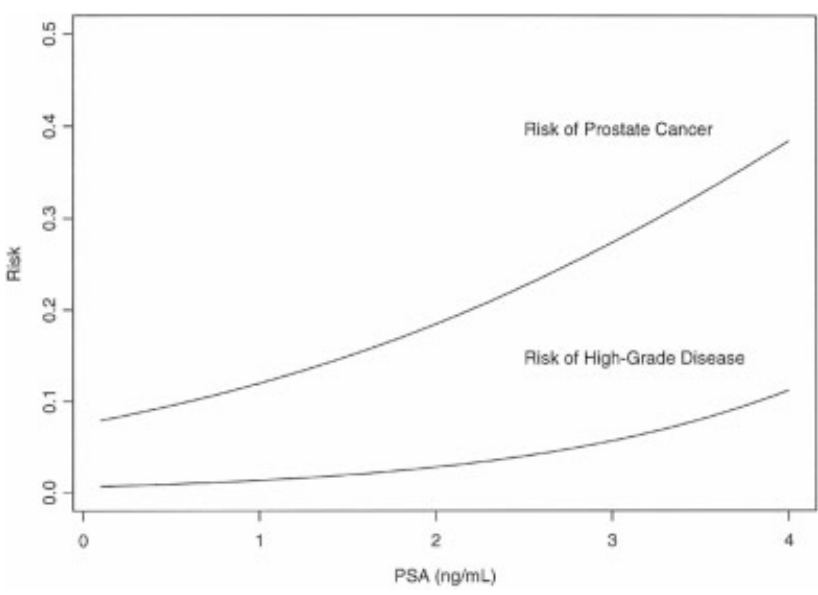

FIGURE 2. Risk of Prostate Cancer and Risk of High-grade Disease by Prostate-specific Antigen (PSA) Level (Based on the Placebo Group of the Prostate Cancer Prevention Trial). Reprinted with permission from Thompson IM, Pauler DK, Goodman PJ, et al. Prevalence of prostate cancer among men with a prostate-specific antigen level $<$ or $=4.0 \mathrm{ng}$ per milliliter. N Eng/ J Med. 2004;350:2239-2246.

PSA threshold for biopsy is $4.0 \mathrm{ng} / \mathrm{mL}$. How a PSA level of $4.0 \mathrm{ng} / \mathrm{mL}$ was reached as a consensus for determining if a man was "normal" or "abnormal" is complex. ${ }^{47}$ Proposed upper limits of normal have ranged from $2.5 \mathrm{ng} / \mathrm{mL}$ to $10.0 \mathrm{ng} / \mathrm{mL} .48,49$

In 2003, the results of the Prostate Cancer Prevention Trial (PCPT) were published. The study randomized 18,882 men to the oral $5-\alpha$ reductase inhibitor finasteride or placebo. The purpose was to determine whether 7 years of treatment with finasteride could reduce the risk of prostate cancer. ${ }^{50}$ Because finasteride reduces PSA, the study included a prostate biopsy in all men at the end of their 7 years of participation, regardless of their PSA and DRE findings. The study was closed 15 months prior to study completion due to evidence that the primary objective had been met: finasteride reduced the risk of prostate cancer by $24.8 \%$. In 2004, an analysis of the risk of prostate cancer across all PSA levels was published. ${ }^{51}$ As displayed in Figure 2, PSA is not a "normal" or "abnormal" test but, like many other screening blood tests (eg, cholesterol), the higher the level of PSA, the higher the risk of cancer and the higher the risk of aggressive, high-grade disease.

This observation is important to the issue of screening. Although the risk of prostate cancer and of high-grade, aggressive cancer increases even further beyond a PSA of $4.0 \mathrm{ng} / \mathrm{mL}$, the majority of the US population $(>90 \%)$ have a PSA value $<4.0 \mathrm{ng} / \mathrm{mL} .{ }^{52}$ As a result, at any point in time, the majority of 


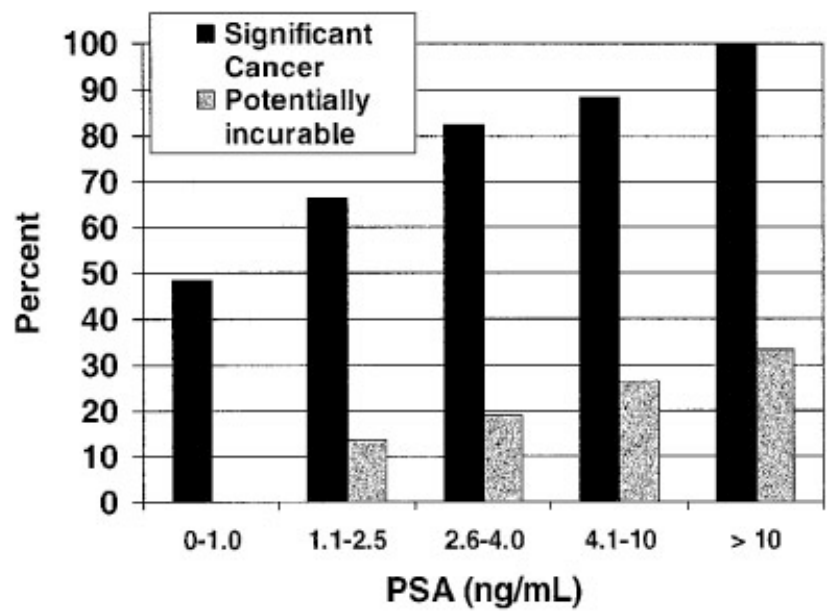

FIGURE 3. Proportion of Cancers Fulfilling Histologic Criteria for Clinical Significance and Incurability by Prostate-specific Antigen (PSA) Level at Diagnosis. Reprinted with permission from Lucia MS, Darke AK, Goodman PJ, et al. Pathologic characteristics of cancers detected in The Prostate Cancer Prevention Trial: implications for prostate cancer detection and chemoprevention. Cancer Prev Res (Phila Pa). 2008;1:167-173.

prostate cancers as well as the majority of the aggressive, most lethal cancers are present in men with a PSA level $<4.0 \mathrm{ng} / \mathrm{mL}$.

A criticism of this observation and its clinical implication (that consideration should be given to a lower "normal" level of PSA) is that clinicians can continue to use a level of $\geq 4.0 \mathrm{ng} / \mathrm{mL}$ to recommend biopsy and still detect the tumor in time to cure it. A second criticism of using lower levels of PSA is that the vast majority of cancers detected at lower levels tend to be "insignificant" and of no clinical consequence. If true, detection would only increase treatment rates, but have no effect on death rates or morbidity.

A recent analysis of the PCPT suggests this criticism to be incorrect. Using the most common definition of "significant" cancer, even at very low PSA levels, the majority of cancers detected were found to meet the criteria of "significant disease."53 More concerning was the observation that, as PSA increased, even at levels far below $4.0 \mathrm{ng} / \mathrm{mL}$, the rate of cancers that were no longer curable increased. Indeed, with PSA levels in the range of 2.6 to $4.0 \mathrm{ng} / \mathrm{mL}, 20 \%$ were categorized as no longer curable when detected (Fig. 3). It is important to understand that these data are based on a histologic definition of "significant" cancer; given the rates of significant cancer at low levels of PSA, it would appear that many "histologically significant" cancers will never progress to symptoms or death.

The worrisome conclusion of these observations is that screening with PSA using a single upper limit of normal of $4.0 \mathrm{ng} / \mathrm{mL}$ may carry a risk of detecting many cancers too late to enable radiation or surgery to cure the disease. In addition, by increasing the rates of prostate biopsy in a population of men in whom prostate cancer was common, rates of cancer detection may have increased but, because the lethal cancers were not detected in time, cancer death rates may not have changed.

Virtually all guidelines regarding screening view PSA and DRE as dichotomous test results, namely, either positive or negative. As such, a man with a PSA level of $4.1 \mathrm{ng} / \mathrm{mL}$ is recommended to undergo a biopsy whereas another man with a PSA level of 3.9 $\mathrm{ng} / \mathrm{mL}$ is considered normal. Similarly, a man with a nodule detected on DRE is recommended to undergo a biopsy regardless of whether his PSA is 0.2 $\mathrm{ng} / \mathrm{mL}$ or $9.8 \mathrm{ng} / \mathrm{mL}$. Other known risk factors are generally not included in the decision to recommend a biopsy. Other risk factors that might be helpful could include whether there is a family history of prostate cancer (an affected first-degree relative doubles the risk of developing prostate cancer), race/ ethnicity (African American men have a significantly greater risk of disease and a greater risk of death from prostate cancer), and age (the risk of prostate cancer increases with age). 54

It is now possible to integrate these other risk factors into tools that estimate an individual man's risk of cancer and his risk of aggressive, high-grade cancer. Among several tools is the PCPT Risk Calculator (available at: http://deb.uthscsa.edu/URORiskCalc/ Pages/uroriskcalc.jsp). This tool was based on 5,519 men from the PCPT placebo arm who all underwent a prostate biopsy, regardless of DRE and PSA findings, and for whom all data elements were available. ${ }^{55}$ Variables found to predict the risk of prostate cancer included PSA, family history, history of prior negative biopsy, and abnormal DRE, whereas variables that were found to predict the risk of high-grade cancer included PSA, DRE, age, African American ethnicity, and history of prior negative biopsy. Given that approximately two-thirds of prostate cancer deaths occur in men whose initial biopsy detected high-grade disease, if the prevention of death due to prostate cancer is a goal of screening, careful attention should be given to those variables associated with the risk of developing highgrade cancer.

To understand how this PCPT analysis demonstrates that naïveté of using PSA and DRE as either 
"positive" or "negative," several patient examples are illustrative. Patient A is a 55-year-old white man with a PSA level of $0.3 \mathrm{ng} / \mathrm{mL}$, no prior prostate biopsy, a negative family history, and a prostate nodule. Patient B is a 68-year-old African American man with a PSA level of $2.4 \mathrm{ng} / \mathrm{mL}$, no prior biopsy, a positive family history, and normal DRE findings. Using current guidelines, Patient A will receive a biopsy recommendation, whereas Patient $\mathrm{B}$ will be told "You're OK." The PCPT Risk Calculator estimates that Patient A's risk of prostate cancer is $13 \%$ and his risk of high-grade cancer is $1 \%$. Patient B's risk of prostate cancer is $31 \%$, and his risk of highgrade cancer is $11 \%$. The benefit of using the PCPT Risk Calculator becomes most evident among men who have a collection of risk factors that increase their risk of high-grade disease, especially in African American and in healthy older men.

\section{Age and Prostate Cancer Risk}

It is generally believed that those men most likely to benefit from the early detection of prostate cancer are those who are youngest and who would live the longest to experience harm from their cancers. As a result of this concern, many guidelines have historically suggested using lower PSA values to prompt a biopsy in these men. ${ }^{55}$ Conversely, it is also believed that older men with other comorbidities and shorter life expectancies should be screened less, using higher PSA values to prompt a biopsy, if at all. For example, a PSA level of $2.5 \mathrm{ng} / \mathrm{mL}$ is often used in men in their 50s to prompt a biopsy, whereas in men in their 70s, higher levels of 5.5 to $6.5 \mathrm{ng} / \mathrm{mL}$ are often used. ${ }^{55}$

The challenge with this approach is that age is a strong predictor of the risk of aggressive cancer. ${ }^{56}$ Using more intensive screening in younger men with lower PSA levels will result in the detection of predominantly low-grade, potentially inconsequential cancers. Conversely, using higher levels of PSA to prompt a biopsy in older men will result in significantly higher rates of aggressive cancer going undetected, especially when applied to African American men. The 2 risks of using PSA age-related cutoff values for PSA instead of incorporating all risk variables is that younger men are increasingly likely to be diagnosed with inconsequential tumors, whereas older men may ultimately be found to have aggressive, potentially lethal cancers that are diagnosed too late to allow curative treatments to be given. Two sobering statistics attest to this risk in older men. First, a 78-year-old man in the United States has a median survival of 10 years; if he is in good health, it is 15 years. ${ }^{8}$ Second, the median age at death from prostate cancer in the United States is 80 years (approximately half of prostate cancer deaths occur after age 80 years). Given that death from prostate cancer is most commonly due to aggressive tumors that develop, grow, and spread in a shorter period of time, the current focus on detection in younger men, in whom slow-growing tumors are more common, may have missed the mark in our goal to prevent deaths from cancer. ${ }^{57}$

\section{Other PSA Tests}

There have been several efforts to improve the accuracy of PSA as a screening test. PSA velocity or an increase in serum PSA levels over time has been assessed because velocity appears to be higher in men with prostate cancer compared with men without the disease. Studies have suggested that PSA velocity is correlated with cancer diagnosis, but adds little to the diagnostic accuracy of PSA alone. ${ }^{58} \mathrm{~A}$ fast-rising PSA does appear to correlate with more aggressive disease and this is best demonstrated in men who have been treated for prostate cancer. One study demonstrated that a rise of 2 $\mathrm{ng} / \mathrm{mL}$ in the year prior to diagnosis increases the risk of prostate cancer death. ${ }^{59}$ PSA doubling time is a variant on PSA velocity. ${ }^{60}$

Prostate cancers produce more PSA per volume of tissue than benign prostate tissues. PSA value adjusted for prostate volume (PSA density) has been advocated as a discriminator between cancer and noncancer causes of PSA elevation. PSA density requires the placement of a probe into the rectum to image the prostate and measure prostate volume; therefore, this more invasive procedure is not routinely performed. ${ }^{61}$

PSA is found both circulating free in serum as well as bound to a macromolecule, $\alpha-1$-antichymotripsin. The free-to-total PSA ratio is lower in men with prostate cancer. It has been proposed as a method to help determine which men with a PSA level of 4.0 to $10.0 \mathrm{ng} / \mathrm{mL}$ should undergo a biopsy. Unfortunately, the percent free PSA appears to be most useful at extreme ratios. ${ }^{62}$ The measurement of complexed (bound) PSA has also been studied and may provide 
marginally better specificity for cancer than total PSA. ${ }^{63}$ Race-specific PSA levels have been proposed but have not been widely accepted. 55,64

\section{The Future of Prostate Cancer Screening}

The future of controlling prostate cancer can be observed through research efforts that are currently ongoing. These include the following:

\section{Better Biomarkers}

Paraphrasing Willet Whitmore, MD, the "father of American urologic oncology," the goal of the early detection of prostate cancer is to find those tumors that need to be cured at a point at which cure is possible. ${ }^{65}$ The first step in achieving this goal is to develop tests, often biomarkers, that are not just reflective of the presence of cancer but the presence of aggressive, potentially lethal cancer. The best surrogate for these aggressive tumors currently available is tumor grade, measured by the Gleason score; highgrade tumors are either Gleason grades 7 to 10 or 8 to 10 . As such, biomarkers that help promote detection efforts in men with high-grade disease, and that would further identify those tumors that will indeed progress if left untreated, would be most useful. Of note, PSA does play a role in that it performs better as a biomarker for the detection of high-grade disease. ${ }^{66} \mathrm{~A}$ range of other markers have demonstrated promise in this regard as well. ${ }^{67}$ These include the glutathione S-transferase pi gene (GSTP1), ${ }^{68}$ prostate cancer antigen 3 (PCA3), ${ }^{69}$ and sarcosine. ${ }^{70}$

Ultimately, an important step in improving the detection of potentially lethal prostate cancer will be through merging these markers into a collective measure of the risk of high-grade disease. Unfortunately, Gleason score is an imperfect measure of risk and does not always predict outcome of the disease. A concurrent effort is necessary to discover and validate biomarkers for their association with the primary outcome of interest: mortality or morbidity. To that end, several studies are currently ongoing. One is a collaboration between the Canary Foundation and the Early Detection Research Network of the NCI. ${ }^{71}$ In this study, a large group of men who have opted for active surveillance of their prostate cancers are being extensively characterized using a range of biologic and clinical measures. With prolonged fol- low-up of these men, it will be possible to discover and possibly validate biomarkers that predict the presence of not just prostate cancer, but potentially lethal disease.

\section{Risk Assessment}

Very few men will develop complications or die from prostate cancer. The screening of these men is not just unnecessary but costly, and leads to the overdetection of cancer and treatment-related complications, as well as a lifelong status of being a cancer survivor, with the psychologic consequences. A superior approach would be to identify those men who are at risk of lethal cancer early in life and potentially apply those cancer biomarkers early and regularly to detect the disease early.

\section{Prevention}

It should be clear from this discussion that the early detection and treatment of prostate cancer is not a simple strategy for controlling this disease, especially because a majority of men will develop the disease during their lifetime yet few will suffer complications, even without detection and treatment. An approach that is attractive to many men is prevention. Although the recent publication of the results of the Selenium and Vitamin E Cancer Prevention Trial indicated that neither selenium nor vitamin $\mathrm{E}$ reduced the risk of prostate cancer, there is 1 proven method to reduce a man's risk of this disease: finasteride. ${ }^{72}$ The PCPT demonstrated that a daily $5-\mathrm{mg}$ dose, which is the dose used clinically for the treatment of urinary symptoms related to prostate enlargement, reduces a man's risk of developing prostate cancer by approximately $25 \% .{ }^{50}$ Initial results found a higher risk of aggressive (high-grade) cancer, but subsequent analyses proved that this was due to finasteride's effect on PSA, DRE, and prostate biopsy to improve the detection of high-grade disease. Multiple analyses have now demonstrated that the cumulative impact of finasteride is to reduce the risk of cancer overall as well as most likely reduce the risk of high-grade disease. ${ }^{73,74}$ Whether finasteride reduces death from prostate cancer to our knowledge is unknown. As noted in a recent editorial, finasteride is safe and effective and should be offered as a prevention option to men at risk of developing prostate cancer. ${ }^{75}$ A recent American Society of Clinical On- 
cology/American Urological Association Clinical Practice Guideline recommends that men who are undergoing PSA screening should be informed of this opportunity for the prevention of prostate cancer. ${ }^{76}$

As a part of an overall strategy to reduce death and suffering from prostate cancer, the prevention of the disease with finasteride may be selected by some men as an integral component of their approach to this disease, especially with the complexity and unclear advantages of early detection and treatment.

\section{What Should a Physician Do?}

For patients potentially interested in prostate cancer screening, physicians should engage them in shared decision-making; this is of even greater importance given the outcomes of the recent reports from the US and European screening studies. It is difficult for physicians to provide comprehensive and balanced information concerning prostate cancer screening decisions during a brief clinic visit. The American Col- lege of Physicians has published a useful summary of discussion points to consider when counseling patients about prostate cancer screening ${ }^{41}$ :

- Prostate cancer is an important health problem.

- The benefits of 1-time or repeated screening and aggressive treatment of prostate cancer have not yet been proven.

- DRE and PSA measurements can have both falsepositive and false-negative results.

- The probability that further invasive evaluation will be required as a result of testing is relatively high.

- Aggressive therapy is necessary to realize any benefit from the discovery of a tumor.

- A small but finite risk for early death and a significant risk for chronic illness, particularly with regard to sexual and urinary function, are associated with these treatments.

- Early detection may save lives.

- Early detection and treatment may avert future cancer-related illness.

\section{References}

1. Jemal A, Siegel R, Ward E, et al. Cancer statistics, 2009. CA Cancer J Clin. 2009;59 (in press).

2. Petrylak DP. The current role of chemotherapy in metastatic hormone-refractory prostate cancer. Urology. 2005;65:3-7.

3. Young HH. Early diagnosis and radical cure of carcinoma of the prostate. Bull Johns Hopkins Hosp. 1905;16:314-321.

4. Thompson IM, Ernst JJ, Gangai MP, Spence CR. Adenocarcinoma of the prostate: results of routine urological screening. $J$ Urol. 1984;132:690-692.

5. Merrill RM, Weed DL, Feuer EJ. The lifetime risk of developing prostate cancer in white and black men. Cancer Epidemiol Biomarkers Prev. 1997;6:763-768.

6. Ries LAG, Melbert D, Krapcho M, et al, eds. SEER Cancer Statistics Review, 1975-2005. Surveillance, Epidemiology, and End Results. Bethesda, Md: National Cancer Institute; 2008.

7. Delongchamps NB, Singh A, Haas GP. Epidemiology of prostate cancer in Africa: another step in the understanding of the disease? Curr Probl Cancer. 2007;31:226-236.

8. Central Intelligence Agency. The World Factbook. Rank Order Life Expectancy at Birth. Washington, DC: Central Intelligence Agency; 2009.

9. Catalona WJ, Smith DS, Ratliff TL, et al. Measurement of prostate-specific antigen in serum as a screening test for prostate cancer. N Engl J Med. 1991;324:1156-1161.

10. Brawer MK, Chetner MP, Beatie J, Buchner DM, Vessella RL, Lange PH. Screening for prostatic carcinoma with prostate specific antigen. J Urol. 1992;147:841-845.

11. Catalona WJ, Richie JP, deKernion JB, et al. Comparison of prostate specific antigen concentration versus prostate specific antigen density in the early detection of prostate cancer: receiver operating characteristic curves. J Urol. 1994;152:2031-2036.

12. Merrill RM, Weed DL. Measuring the public health burden of cancer in the United States through lifetime and age-conditional risk estimates. Ann Epidemiol. 2001;11:547-553.

13. Smith RA, Cokkinides V, Brawley OW. Cancer screening in the United States, 2008: a review of current American Cancer Society guidelines and cancer screening issues. CA Cancer J Clin. 2008;58:161-179.

14. Ross LE, Berkowitz Z, Ekwueme DU. Use of the prostate-specific antigen test among U.S. men: findings from the 2005 National Health Interview Survey. Cancer Epidemiol Biomarkers Prev. 2008;17:636-644.

15. Edwards BK, Brown ML, Wingo PA, et al. Annual report to the nation on the status of cancer, 1975-2002, featuring populationbased trends in cancer treatment. J Natl Cancer Inst. 2005;97:1407-1427.

16. Lu-Yao GL, Friedman M, Yao SL. Use of radical prostatectomy among Medicare beneficiaries before and after the introduction of prostate specific antigen testing. J Urol. 1997;157:2219-2222

17. Denberg TD. Re: racial/ethnic disparities in the treatment of localized/regional prostate cancer. J Urol. 2004;172:1547-1548.

18. Cooperberg MR, Lubeck DP, Meng MV, Mehta SS, Carroll PR. The changing face of low-risk prostate cancer: trends in clinical presentation and primary management J Clin Oncol. 2004;22:2141-2149.

19. Klabunde CN, Potosky AL, Harlan LC, Kramer BS. Trends and black/white differences in treatment for nonmetastatic prostate cancer. Med Care. 1998;36:1337-1348.

20. Shavers VL, Brown M, Klabunde CN, et al. Race/ethnicity and the intensity of medical monitoring under 'watchful waiting' for prostate cancer. Med Care. 2004;42:239-250.

21. Wilt TJ. Prostate carcinoma practice patterns: what do they tell us about the diagnosis, treatment, and outcomes of patients with prostate carcinoma? Cancer. 2000;88:1277-1281.

22. Potosky AL, Davis WW, Hoffman RM, et al. Five-year outcomes after prostatectomy or radiotherapy for prostate cancer: the prostate cancer outcomes study. J Natl Cancer Inst. 2004;96:1358-1367.

23. Boyle P. Screening for prostate cancer: have you had your cholesterol measured? BJU Int. 2003;92:191-199.

24. Moul JW, Connelly RR, Lubeck DP, et al Predicting risk of prostate specific antigen recurrence after radical prostatectomy with the Center for Prostate Disease Research and Cancer of the Prostate Strategic Urologic Research Endeavor databases. J Urol. 2001;166:1322-1327.

25. Wood HM, Reuther AM, Gilligan TD, et al Rates of biochemical remission remain higher in black men compared to white men after radical prostatectomy despite similar trends in prostate specific antigen induced stage migration. J Urol. 2007;178: 1271-1276.

26. Lu-Yao GL, Potosky AL, Albertsen PC, et al. Follow-up prostate cancer treatments after 
radical prostatectomy: a population-based study. J Natl Cancer Inst. 1996;88:166-173.

27. Etzioni R, Tsodikov A, Mariotto A, et al. Quantifying the role of PSA screening in the US prostate cancer mortality decline. Cancer Causes Control. 2008;19:175-181.

28. Concato J, Wells CK, Horwitz RI, et al. The effectiveness of screening for prostate cancer: a nested case-control study. Arch Intern Med. 2006;166:38-43.

29. Marcella SW, Rhoads GG, Carson JL, Merlino F, Wilcox H. Prostate-specific antigen screening and mortality from prostate cancer. J Gen Intern Med. 2008;23:248 -253.

30. Weinmann S, Richert-Boe K, Glass AG, Weiss NS. Prostate cancer screening and mortality: a case-control study (United States). Cancer Causes Control. 2004;15:133-138.

31. Kopec JA, Goel V, Bunting PS, et al. Screening with prostate specific antigen and metastatic prostate cancer risk: a population based case-control study. J Urol. 2005;174:495-499.

32. Seidenfeld J, Samson DJ, Hasselblad V, et al. Single-therapy androgen suppression in men with advanced prostate cancer: a systematic review and meta-analysis. Ann Intern Med. 2000;132:566-577.

33. Bartsch G, Horninger W, Klocker H, et al. Tyrol Prostate Cancer Demonstration Project: early detection, treatment, outcome, incidence and mortality. BJU Int. 2008;101:809-816.

34. Collin SM, Martin RM, Metcalfe C, et al. Prostate-cancer mortality in the USA and UK in 1975-2004: an ecological study. Lancet Oncol. 2008;9:445-452.

35. Lu-Yao G, Albertsen PC, Stanford JL, et al. Screening, treatment, and prostate cancer mortality in the Seattle area and Connecticut: fifteen-year follow-up. J Gen Intern Med. 2008;23:1809-1814.

36. Etzioni R, Penson DF, Legler JM, et al. Overdiagnosis due to prostate-specific antigen screening: lessons from U.S. prostate cancer incidence trends. J Natl Cancer Inst. 2002;94:981-990.

37. Draisma G, Boer R, Otto SJ, et al. Lead times and overdetection due to prostate-specific antigen screening: estimates from the European Randomized Study of Screening for Prostate Cancer. J Natl Cancer Inst. 2003;95: $868-878$.

38. Ward E, Halpern $\mathrm{M}$, Schrag $\mathrm{N}$, et al. Association of insurance with cancer care utilization and outcomes. CA Cancer J Clin. 2008;58:9-31.

39. Begg CB, Riedel ER, Bach PB, et al. Variations in morbidity after radical prostatectomy. N Engl J Med. 2002;346:1138-1144.

40. Lu-Yao GL, Albertsen P, Warren J, Yao SL. Effect of age and surgical approach on complications and short-term mortality after radical prostatectomy-a populationbased study. Urology. 1999;54:301-307.

41. Harris R, Lohr KN. Screening for prostate cancer: an update of the evidence for the U.S. Preventive Services Task Force. Ann Intern Med. 2002;137:917-929.

42. Stanford JL, Noonan EA, Iwasaki L, et al. A polymorphism in the CYP17 gene and risk of prostate cancer. Cancer Epidemiol Biomarkers Prev. 2002;11:243-247.

43. Thompson IM, Thrasher JB, Aus G, et al. Guideline for the Management of Clinically Localized Prostate Cancer. Linthicum, Md: American Urological Association; 2007 update. J Urol. 2007;177:2186-31.
44. Andriole GL, Grubb RL III, Buys SS, et al. Mortality results from a randomized prostate-cancer screening trial. $N$ Engl J Med. 2009;360:1310-1319.

45. Schroder FH, Hugosson J, Roobol MJ, et al. Screening and prostate-cancer mortality in a randomized European study. $N$ Engl JMed. 2009;360:1320-1328.

46. Eichler K, Hempel S, Wilby J, et al. Diagnostic value of systematic biopsy methods in the investigation of prostate cancer: a systematic review. JUrol. 2006;175:1605-1612.

47. Kolata G. It was medical gospel, but it wasn't true. New York Times. May 30, 2004;§4:7.

48. Carvalhal GF, Smith DS, Mager DE, Ramos C, Catalona WJ. Digital rectal examination for detecting prostate cancer at prostate specific antigen levels of $4 \mathrm{ng} . / \mathrm{ml}$. or less. J Urol. 1999;161:835-839.

49. Gilbert SM, Benson MC, McKiernan JM. Linkage disequilibrium between the androgen receptor gene CAG and GGC repeats in the African-American population. Curr Urol Rep. 2002;3:189-193.

50. Thompson IM, Goodman PJ, Tangen CM, et al. The influence of finasteride on the development of prostate cancer. $N$ Engl JMed. 2003;349:215-224.

51. Thompson IM, Pauler DK, Goodman PJ, et al. Prevalence of prostate cancer among men with a prostate-specific antigen level $<$ or $=4.0 \mathrm{ng}$ per milliliter. $N$ Engl $J$ Med. 2004;350:2239-2246.

52. Porter MP, Stanford JL, Lange PH. The distribution of serum prostate-specific antigen levels among American men: implications for prostate cancer prevalence and screening. Prostate. 2006;66:1044-1051.

53. Lucia MS, Darke AK, Goodman PJ, et al. Pathologic characteristics of cancers detected in The Prostate Cancer Prevention Trial: implications for prostate cancer detection and chemoprevention. Cancer Prev Res (Phila Pa). 2008;1:167-173.

54. Giovannucci E, Liu Y, Platz EA, Stampfer MJ, Willett WC. Risk factors for prostate cancer incidence and progression in the health professionals follow-up study. Int $J$ Cancer. 2007;121:1571-1578

55. Morgan TO, Jacobsen SJ, McCarthy WF, et al. Age-specific reference ranges for prostate-specific antigen in black men. $N$ Engl J Med. 1996;335:304-310.

56. Parekh DJ, Ankerst DP, Higgins BA, et al. External validation of the Prostate Cancer Prevention Trial risk calculator in a screened population. Urology. 2006;68:1152-1155.

57. Reed A, Ankerst DP, Pollock BH, Thompson IM, Parekh DJ. Current age and race adjusted prostate specific antigen threshold values delay diagnosis of high grade prostate cancer. J Urol. 2007;178:1929-1932.

58. Pinsky PF, Andriole G, Crawford ED, et al. Prostate-specific antigen velocity and prostate cancer gleason grade and stage. Cancer. 2007;109:1689-1695

59. D'Amico AV, Chen MH, Roehl KA, Catalona WJ. Identifying patients at risk for significant versus clinically insignificant postoperative prostate-specific antigen failure. J Clin Oncol. 2005;23:4975-4979.

60. Etzioni RD, Ankerst DP, Weiss NS, Inoue LY, Thompson IM. Is prostate-specific antigen velocity useful in early detection of prostate cancer? A critical appraisal of the evidence. J Natl Cancer Inst. 2007;99: $1510-1515$.
61. Stephan C, Stroebel G, Heinau M, et al. The ratio of prostate-specific antigen (PSA) to prostate volume (PSA density) as a parameter to improve the detection of prostate carcinoma in PSA values in the range of $<4$ ng/mL. Cancer. 2005;104:993-1003.

62. Lee R, Localio AR, Armstrong K, Malkowicz SB, Schwartz JS. A meta-analysis of the performance characteristics of the free prostate-specific antigen test. Urology. 2006;67: 762-768.

63. Partin AW, Brawer MK, Bartsch G, et al. Complexed prostate specific antigen improves specificity for prostate cancer detection: results of a prospective multicenter clinical trial. J Urol. 2003;170:1787-1791.

64. Catalona WJ, Richie JP, Ahmann FR, et al. Comparison of digital rectal examination and serum prostate specific antigen in the early detection of prostate cancer: results of a multicenter clinical trial of 6,630 men. J Urol. 1994;151:1283-1290.

65. Whitmore WF, Jr. Natural history of lowstage prostatic cancer and the impact of early detection. Urol Clin North Am. 1990; $17: 689-697$.

66. Thompson IM, Ankerst DP, Chi C, et al Operating characteristics of prostate-specific antigen in men with an initial PSA level of $3.0 \mathrm{ng} / \mathrm{ml}$ or lower. JAMA. 2005 ; 294:66-70.

67. Parekh DJ, Ankerst DP, Troyer D, Srivastava S, Thompson IM. Biomarkers for prostate cancer detection. J Urol. 2007;178: 2252-2259.

68. Mallick S, Romana M, Blanchet P, Multigner L. GSTM1 and GSTT1 polymorphisms and the risk of prostate cancer in a Caribbean population of African descent. Urology. 2007;69:1165-1169.

69. Ankerst DP, Groskopf J, Day JR, et al. Predicting prostate cancer risk through incorporation of prostate cancer gene 3 . J Urol. 2008;180:1303-1308,

70. Sreekumar A, Poisson LM, Rajendiran TM et al. Metabolomic profiles delineate potential role for sarcosine in prostate cance progression. Nature. 2009;457:910-914.

71. Canary Foundation. Palo Alto, Calif: Canary Foundation; May 15, 2009. http:// www.canaryfoundation.org.

72. Lippman SM, Klein EA, Goodman PJ, et al. Effect of selenium and vitamin $E$ on risk of prostate cancer and other cancers: the Selenium and Vitamin E Cancer Prevention Trial (SELECT). JAMA. 2009;301:39-51.

73. Redman MW, Tangen CM, Goodman PJ, et al. Finasteride does not increase the risk of high-grade prostate cancer: a bias-adjusted modeling approach. Cancer Prev Res (Phila Pa). 2008;1:174-181.

74. Cohen YC, Liu KS, Heyden NL, et al Detection bias due to the effect of finasteride on prostate volume: a modeling approach for analysis of the Prostate Cancer Prevention Trial. J Natl Cancer Inst. 2007;99: $1366-1374$

75. Logothetis CJ, Schellhammer PF. Highgrade prostate cancer and the prostate cancer prevention trial. Cancer Prev Res (Phila Pa). 2008;1:151-152.

76. Kramer BS, Hagerty KL, Justman S, et al. Use of 5alpha-reductase inhibitors for prostate cancer chemoprevention: American Society of Clinical Oncology/American Urological Association 2008 Clinical Practice Guideline. J Urol. 2009;181:1642-1657. 